\title{
Audit Operasional Pelayanan Pada PT. XYZ Dengan Menggunakan Kerangka Kerja ITIL Service Operation
}

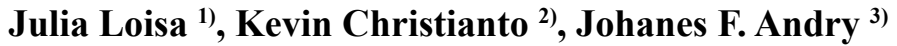 \\ Sistem Informasi, Fakultas Teknologi dan Desain, Universitas Bunda Mulia \\ Jalan Lodan Raya No.2, Jakarta Utara, 14430 \\ ${ }^{1)}$ Email: jloisa@bundamulia.ac.id \\ 2)Email:kchristianto@bundamulia.ac.id \\ ${ }^{3)}$ Email: jandry@bundamulia.ac.id
}

\begin{abstract}
This research was investigated to conduct an audit operational IT service management. Service has become a special key in forming a good organizational environment, there have been many studies that prove that a good level of service is directly proportional to loyalty, productivity, etc. from end users. In this study focused on the operational processes of the information system services provided by the company to all stakeholders of the information system users, because the operational side is the spearhead of the service process that is reached by stakeholders. The researcher conducted $a$ literature study, interviews, observations, questionnaires, examined documents and analyzed the results of questionnaires and document checks to obtain factual data from the field which would later be used as risk analysis and recommendations for solutions to be provided by researchers. The researcher himself uses the ITIL v3 framework which focuses on the Service Operation which will be matched with the information system service commitments contained in the Service Level Agreement.
\end{abstract}

Keywords: ITIL v3, manajemen pelayanan TI, service operation

\begin{abstract}
Abstrak: Penelitian ini diteliti untuk melakukan audit manajemen operasional pelayanan TI. Pelayanan menjadi salah satu kunci khusus dalam membentuk lingkungan organisasi yang baik, sudah banyak penelitian yang membuktikan bahwa tingkat pelayanan yang baik berbanding lurus dengan kesetiaan, produktivitas, dan lain-lain dari end user. Pada penelitian ini difokuskan kepada proses operasional dari pelayanan sistem informasi yang diberikan oleh perusahaan kepada seluruh stakeholder pengguna sistem informasi tersebut, karena sisi operasional merupakan ujung tombak dari proses pelayanan yang didapakan oleh stakeholder. Peneliti melakukan studi pustaka, wawancara, observasi, penyebaran kuisioner, pemeriksaan dokumen dan melakukan analisa terhadap hasil penyebaran kuisioner dan pemeriksaan dokumen untuk mendapatkan data faktual dari lapangan yang nanti akan digunakan sebagai analisa resiko dan rekomendasi solusi yang akan diberikan oleh peneliti. Peneliti sendiri menggunakan framework ITIL v3 yang terfokus pada bagian Service Operation yang nanti akan dicocokan dengan komitmen pelayanan sistem informasi yang tertuang pada Service Level Agreement.
\end{abstract}

Kata Kunci: ITIL v3, manajemen pelayanan TI, service operation

\section{PENDAHULUAN}

Sistem informasi manajemen sangat diperlukan untuk operasional suatu perusahaan. Dalam kegiatan pemeliharaan mereka harus menjaga agar sistem tetap tersedia meski keadaan mereka telah berubah dalam operasional bisnis. Awalnya dalam kegiatan pemeliharaan biasanya tidak dikenali sebagai layanan TI [1], [2].

Asal-usul dari manajemen pelayanan sendiri berasal dari pelayanan jasa tradisional seperti perusahaan penerbangan, bank, hotel, dan lainnya. Dan dulunya TI juga hanya difokuskan kepada pengembangan aplikasi saja, dan seluruh kemungkinan manfaat dari TI juga hanya berkutat pada hal tersebut saja. Tetapi pada prakteknya saat ini, hal tersebut sudah di adopsi oleh organisasi TI untuk mengelola pelayanan yang mengelola aplikasi, infrastruktur dan proses TI itu sendiri. Oleh karena itu, pada pengembangan teknologi baru, penyampaian aplikasi juga dilihat sebagai bagian dari penawaran layanan yang lebih besar, yaitu mendukung bisnis itu sendiri sebagai pelayanan TI [3].

Salah satu fenomena spesifik yang menonjol dalam hal ini adalah pengembangan dan proliferasi kerangka acuan pengelolaan sumber daya TI/SI yang disebut Information Technology Infrastructure Library (ITIL). Ini berakar pada serangkaian praktik 
terbaik yang disatukan oleh pemerintah Inggris pada tahun 1980an dan telah berkembang selama bertahun-tahun untuk menjadi standar de facto untuk transisi organisasi TI/SI ke organisasi layanan yang disebutkan di atas. Meskipun tidak memiliki ketelitian, adopsi yang terus berlanjut oleh organisasi TI/SI dalam praktik dapat ditafsirkan sedemikian rupa sehingga memberikan solusi yang memadai untuk serangkaian masalah bagi organisasi layanan TI/SI dan oleh karena itu pada umumnya dapat dianggap "sukses" [4]. Seiring dengan berkembangnya sistem informasi dan teknologi informasi pada saat ini, beberapa hal penting yang menjadi faktor penentu agar sistem yang berjalan dapat befungsi dengan baik dan benar adalah tata kelola keamanan TI yang diterapkan. Sebuah sistem mengumpulkan dan menganalisis data dan menghasilkan laporan yang tujuannya adalah membantu manajemen memecahkan masalah terstruktur [5], [6], [7]. Dengan penelitian ini menggunakan ITIL v3 diharapkan dapat memberikan temuan-temuan, fakta resiko, dan rekomendasi solusi dalam membantu meningkatkan kualitas layanan operasional TI pada PT. XYZ.

Berdasarkan uraian yang telah dipaparkan oleh penulis pada latar belakang masalah dan dirumuskan masalah yang akan dibahas dalam paper ini adalah: Kajian ini bukanlah ditujukan untuk menguji complete conformance dengan ITIL, namun lebih ditujukan untuk mendapatkan gambaran kematangan proses-proses dalam tata kelola layanan berdasarkan perspektif ITIL [8]; Hasil Analisis berupa hasil temuan fakta lapangan, resiko, dan rekomendasi solusi yang sesuai dengan best practices dari ITIL v3; dan Memberikan temuan fakta lapangan, temuan resiko dan rekomendasi solusi best practices dari kinerja operasional yang berjalan di pelayanan TI/SI pada PT. XYZ berdasarkan metode ITIL v3 menggunakan proses Service Operation.

Penelitian ini bertujuan untuk: Melakukan kegiatan audit pada proses operasional pelayanan TI/SI yang berada di PT. XYZ; Melaksanakan kegiatan audit dengan best practices ITIL yang nanti akan dihasilkan temuan fakta, resiko temuan dan rekomendasi solusi; dan Menghasilkan laporan audit yang kompherensif dengan PT. XYZ

\section{METODE PENELITIAN}

Pada Gambar 1. Metode Penelitian, dapat dilihat jika dalam pengerjaan penelitian inidibagimenjadi dua tahap, yaitu tahap I , dimana difokuskan pada bagian penelitian dan tahap II dimana penelitian lanjutan guna membentuk rekomendasi pengembangan guna mengoptimalkan pelayanan operasional TI dengan data yang ada. Kedua tahap tersebut di akhiri dengan tahap terakhir yang terdiri dari kesimpulan, saran.

Untuk lebih detailnya dibahas tiap tahap:

Tahap I, terdiri dari Pengumpulan dokumen, peneliti melakukan pengumpulan jenis dokumen pendukung terhadap pelayanan TI pada PT. XYZ. Kuesioner, dibuat berdasarkan standar yang telah dikembangkan dari bagian ITIL yang disebarkan kepada pemberi layanan dan penerima layanan di PT. XYZ. Dari pengumpulan dokumen dan kuesioner tersebut ditarik gambaran data fakta awal tentang kegiatan audit yang dilakukan pada PT. XYZ.

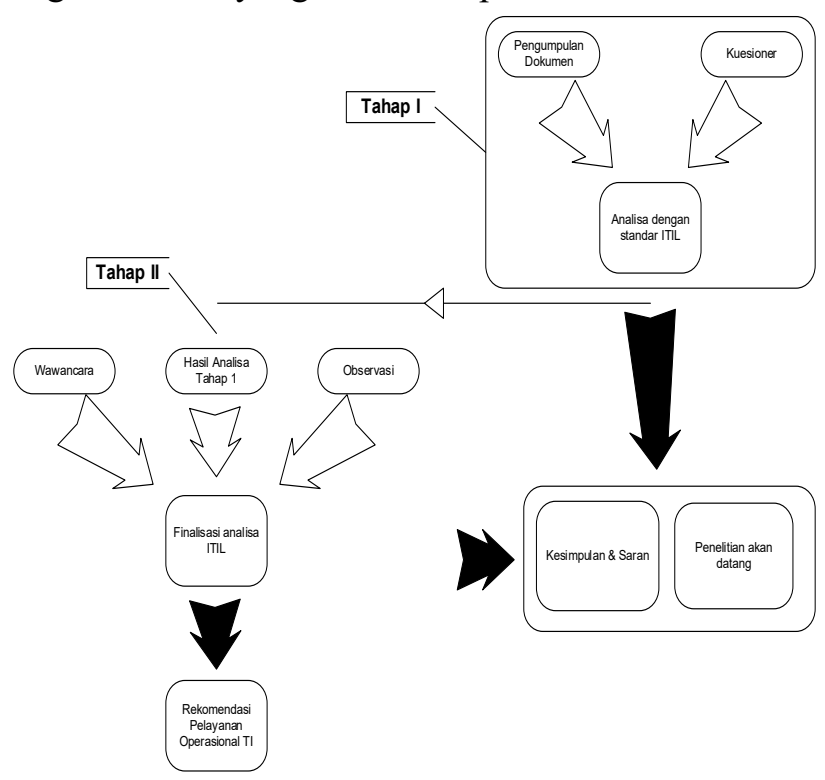

Gambar 1. Metode Penelitian

Tahap II, terdiri dari Wawancara, peneliti melakukan wawancara kepada orang yang bertanggung jawab pada perancangan proses pelayanan operasional TI di PT. XYZ guna mendapatkan gambaran mengenai keadaan saat ini dan konfirmasi hasil penelitian tahap 1. Hasil analisis tahap 1, hasil yang didapat dari data yang sudah diolah akan menjadi data fakta pendukung untuk peneliti merancang rekomendasi pengembangan untuk pelayanan operasional TI untuk PT. XYZ. Observasi, peneliti melakukan observasi didalam dan diluar PT. XYZ tetapi yang masih berkaitan dengan pelayanan operasional TI PT. XYZ secara langsung maupun tidak langsung. Finalisasi analisis dengan standar ITIL, dari data yang telah terkumpul, peneliti melakukan analisis ITIL sebagai acuan untuk pembentukan rekomendasi pengembangan untuk pelayanan operasional TI PT. XYZ. Rekomendasi pelayanan operasional TI, dari analisa ITIL yang dilakukan peneliti membentuk hasil dari penelitian 
ini yaitu berupa rekomendasi dari temuan-temuan yang telah dianalisa oleh peneliti.

Tahap Akhir, didalamnya adalah Kesimpulan \& saran, peneliti memberikan kesimpulan dan saran dari hasil penelitian yang telah dilakukan.

\section{Maturity Level ITIL}

Tabel 1 Maturity level ITIL, menunjukkan tingkat kematangan perusahaan, membantu untuk menentukan tahapan dan level ekspetasi dari control serta membandingkannya dengan standar yang sudah ada [9].

Tabel 1. Maturity Level ITIL [10], [11]

\begin{tabular}{|c|c|c|}
\hline Level & Description & Index \\
\hline $\begin{array}{l}\text { Level 0: } \\
\text { Incomplete } \\
\text { process. }\end{array}$ & $\begin{array}{l}\text { The company is not at } \\
\text { all concerned about the } \\
\text { importance of } \\
\text { information technology } \\
\text { to be managed well by } \\
\text { management }\end{array}$ & $0.00-0,49$ \\
\hline $\begin{array}{l}\text { Level 1: Ad- } \\
\text { Hoc process. }\end{array}$ & $\begin{array}{l}\text { The Company is } \\
\text { reactively doing the } \\
\text { application of } \\
\text { information technology } \\
\text { in accordance with } \\
\text { immediate needs, } \\
\text { without preceded by } \\
\text { planning previous. }\end{array}$ & $0,50-1,50$ \\
\hline $\begin{array}{l}\text { Level 2: } \\
\text { Repeatable } \\
\text { process. }\end{array}$ & $\begin{array}{l}\text { The Company already } \\
\text { has a pattern repeatedly } \\
\text { done in doing } \\
\text { management of activities } \\
\text { related to governance IT }\end{array}$ & $1,50-2,49$ \\
\hline $\begin{array}{l}\text { Level 3: } \\
\text { Defined } \\
\text { process. }\end{array}$ & $\begin{array}{l}\text { The Company already } \\
\text { has the standard } \\
\text { procedure formal and } \\
\text { written communications } \\
\text { to all stakeholders to be } \\
\text { obeyed and done in daily } \\
\text { activities. }\end{array}$ & $2,50-3,49$ \\
\hline $\begin{array}{l}\text { Level 4: } \\
\text { Managed } \\
\text { process. }\end{array}$ & $\begin{array}{l}\text { The Company already } \\
\text { has a number of } \\
\text { indicators which serve } \\
\text { as each target } \\
\text { Application of } \\
\text { information technology } \\
\text { applications. }\end{array}$ & $3,50-4,49$ \\
\hline $\begin{array}{l}\text { Level 5: } \\
\text { Optimized } \\
\text { process. }\end{array}$ & $\begin{array}{l}\text { The Company has } \\
\text { implemented governance } \\
\text { manage the information } \\
\text { Technology that it refers } \\
\text { to "best practice". }\end{array}$ & $4,50-5,00$ \\
\hline
\end{tabular}

Audit Manajemen Operasional pada PT. XYZ adalah proses sistematis untuk memperoleh dan mengevaluasi bukti yang relevan secara obyektif mengenai penilaian berbagai kegiatan ekonomi dan acara untuk memastikan tingkat kesesuaian antara penilaian ini dan kriteria bentuk dan memberikan hasilnya kepada pengguna [12].

\section{HASIL DAN PEMBAHASAN}

Pada pembahasan ini, peneliti akan menjelaskan mengenai hasil analisis maturity level dari temuan peneliti saat melakukan proses audit pada PT.XYZ.

\section{A. Hasil temuan Service Desk}

PT.XYZ secara intuitif sudah memanfaatkan fungsi Service Desk dengan SLA tertentu tetapi semua itu tidak diformalkan dalam dokumen dan kebijakan. Sistem Informasi yang digunakan oleh PT.XYZ ternyata dikelola oleh pihak ketiga. Sehingga aspek layanannya tidak terpantau secara jelas, meskipun telah memiliki SLA. Personil yang melakukannya menjalankannya dengan baik tetapi tidak bertindak sebagai spesialis dalam konteks service desk yang sebenarnya. Pada umumnya personil yang terlibat bertindak karena menganggap bahwa hal itu bagian dari pekerjaan sehari-hari. Semua aktivitas tidak dilakukan dengan prosedur formal.

\section{Service Desk}

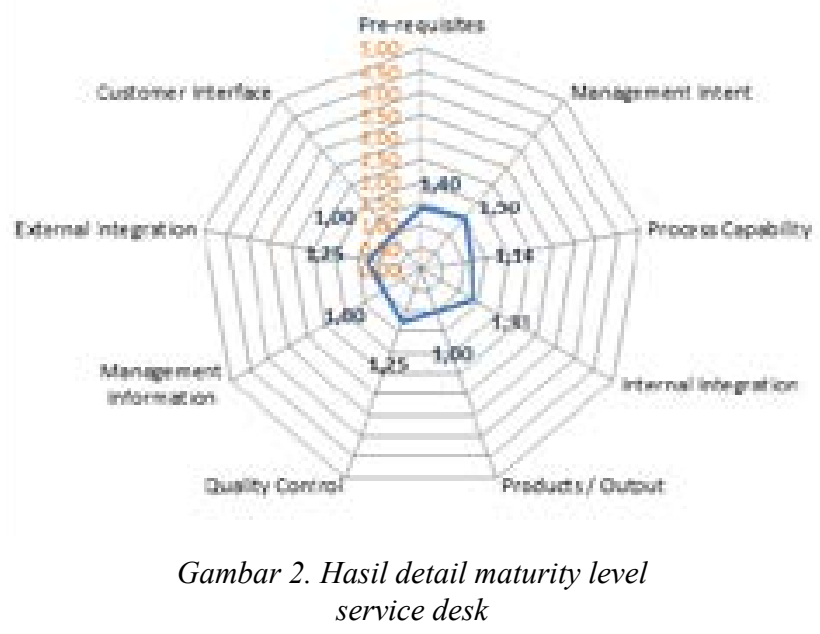

Melihat hasil temuan tersebut peneliti memberikan hasil maturity level total 1.21 dari ratarata keseluruhan penilaian. Salah satu penyebabnya adalah kurangnya niatan dari manajemen terhadap kegitatan operasional sehingga masih didorong dari niatan staf TI yang bertugas. 


\section{B. Hasil temuan Incident Management}

Peneliti tidak menemukan helpdesk resmi untuk menunjang kinerja TI dalam PT. XYZ. Yang berjalan saat ini adalah staf TI yang sedang bertugas saat itu yang menjalankan helpdesk informal dalam PT. XYZ. Dan tidak ada orang khusus TI yang mengurus helpdesk TI untuk masing-masing kasus dalam sistem informasi, jadi permasalahan yang berat tidak dapat dikerjakan langsung oleh stf TI bertugas dan kadang bergantung pada pihak ketiga. Dengan demikian, jika terjadi insiden, tidak dapat diketahui apakah insiden tersebut bisa terselesaikan. Data owner juga tidak jelas dan otorisasi terhadap data. Hal ini mengakibatkan jika terjadi insiden, tidak ada yang bertanggung jawab.

\section{Incident Management}

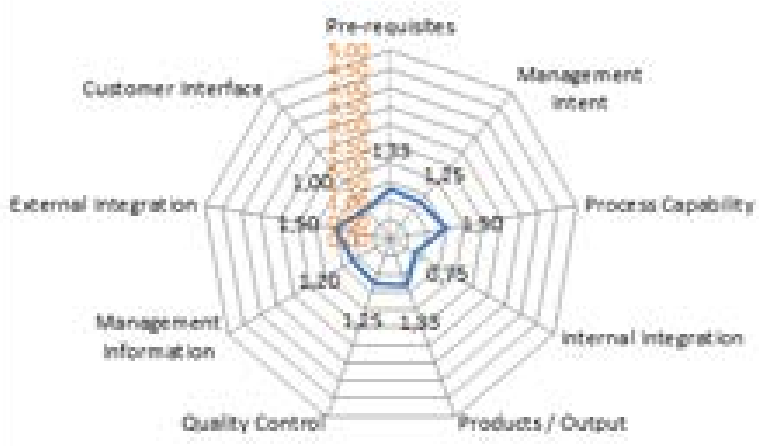

Gambar 3. Hasil detail maturity level incident management

Melihat hasil temuan tersebut peneliti memberikan hasil maturity level total 1.24 dari ratarata keseluruhan penilaian. Salah satu penyebabnya adalah belum jelas dan kurang terlatih staf TI dari PT. XYZ untuk menghadapi insiden spesifik dan kurangnya perhatian dari manajemen untuk masalah selain berhubungan dengan pihak ketiga sehingga staf TI berimprovisasi sendiri.

\section{Hasil temuan Service Level Agreement}

Secara umum, proses Service level Management belum terdefinisi untuk mengelola kesepakatan kinerja layanan (service level agreement) antara manajemen, pengguna layanan, dan penyedia layanan itu sendiri (staf TI). Dokumen service level agreement (SLA) merupakan bagian teknis dari kontrak penyediaan layananpihak ketiga saja yang menjadi acuan kinerja yang mengikat dan dapat memiliki konsekuensi terhadap setiap pencapaian maupun pelanggarannya. SLA di PT. XYZ tidak terdefinisi secara formal.

\section{Service Level Agreement}

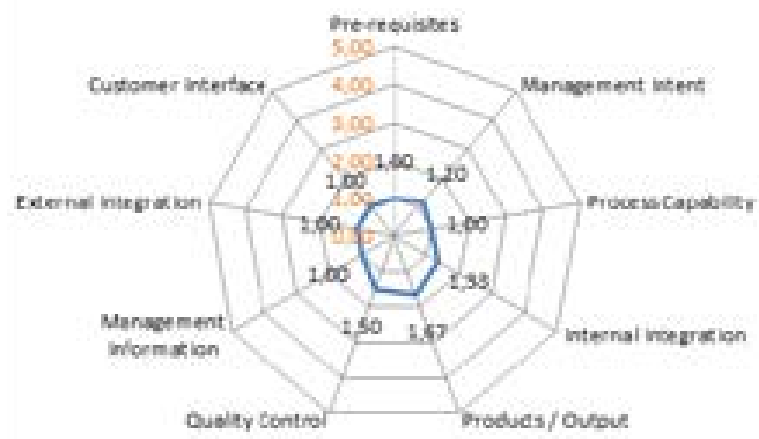

Gambar 4. Hasil detail maturity level service level agreement

Melihat hasil temuan tersebut peneliti memberikan hasil maturity level total 1.19 dari ratarata keseluruhan penilaian. Salah satu penyebabnya adalah belum jelas SLA dalam internal PT. XYZ yang menyebabkan ketidakjelasan pelayanan secara internal perusahaan.

\section{Hasil temuan Change Management}

Secara umum, proses Change Management untuk layanan di PT. XYZ belum berjalan secara baik. Tidak setiap perubahan melalui sebuah prosedur formal pengajuan perubahan untuk kemudian dilakukan analisa dampak dan manfaat, persetujuan, perencanaan sumberdaya dan penjadwalan, implementasi dan antisipasi kegagalan, dan review pasca implementasi.

\section{Change Management}

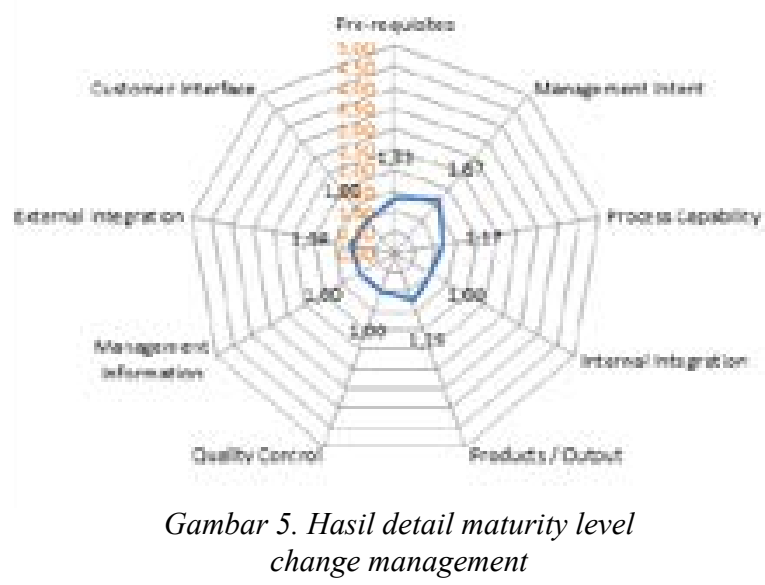

Melihat hasil temuan tersebut peneliti memberikan hasil maturity level total 1.17 dari ratarata keseluruhan penilaian. Salah satu penyebabnya adalah belum jelas manajemen perubahan dalam internal PT. XYZ yang menyebabkan ketidakjelasan perubahan layanan secara internal perusahaan. 


\section{Ringkasan temuan}

PT. XYZ sudah memiliki sistem yang cukup baik tetapi secara management, tetapi aspek layanannya kurang diperhatikan, sehingga banyak layanan yang tidak terdokumentasi, terukur dan paling parah terbengkalai.

\section{Ringkasan ITSM PT. XYZ}

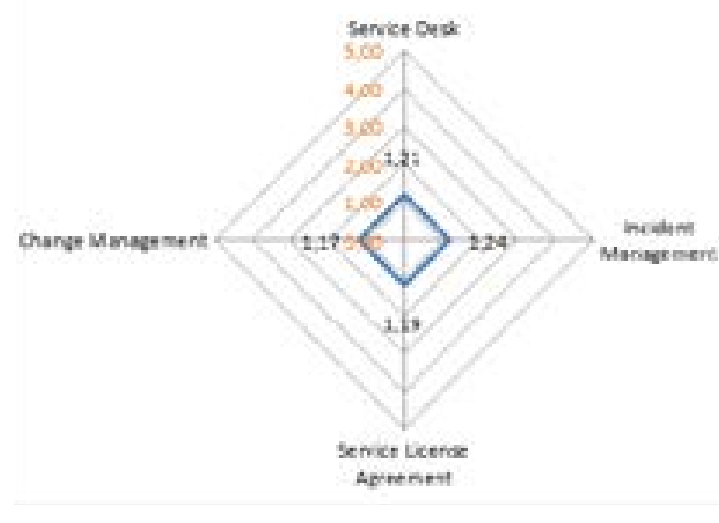

Gambar 5. Hasil ringkasan maturity level

Dari seluruh hasil temuan tersebut peneliti memberikan hasil maturity level total 1.20 dari rata-rata keseluruhan penilaian yang berarti bernilai sangat lemah. Ini karena pelayanan TI seperti belum mendapatkan perhatian dari manajemen.

\section{SIMPULAN}

Berdasarkan hasil penelitian yang telah dilakukan, maka dapat ditarik kesimpulan sebagai berikut: Dari hasil temuan audit oleh peneliti dapat diambil kesimpulan bahwa penerapan layanan TI dalam PT. XYZ masih sangat lemah dengan nilai maturity level sebesar 1.20 untuk service operation internal perusahaan; Dari kesluruhan temuan yang paling mendapat sorotan adalan bagian Service Level Agreement dan Change Management, karena kedua bagian tersebut tidak mendapatkan perhatian sama sekali dari manajemen dan belum dianggap penting. Oleh karena itu, dua bagian tersebut mendapatkan nilai terendah.

Rekomendasi untuk perusahan antara lain: Pertama perlunya dibuatkan dokumentasi formal bagi seluruh aktivitas pelayanan yang ada dalam PT. XYZ, bukan dengen pihak ketiga saja, tetapi juga dengan pihak internal dari perusahaan sendiri; Membentuk bagian khusus helpdesk yang berperan spesifik untuk menjalankan pelayanan TI baik dengan pihak internal maupun eksternal; Perlunya membangun detail prosedural terkait dengan insiden yang sering terjadi dalam PT. XYZ terutama bagaimana solusi dan proses eskalasi dari insiden yang ada.

\section{DAFTAR PUSTAKA}

[1] H. Wada, dan T. Yoshida, "Study On It Service Management At A Polytechnic College", Japan Advanced Institute of Science and Technology, hlm 271, 2012.

[2] M. Ciesielska, "Implementation of ITIL Service Lifecycle in Small And Medium-Sized Enterprises of Polish ICT Sector", Information Systems in Management, hlm 214, 2017.

[3] OGC, "The Official Introduction to the ITIL. United Kingdom", TSO (The Stationery Office), hlm 231, 2007

[4] A. Drechsler, "A Meta-Study on the Effects of Adopting and Using the ITIL Reference Framework on IS/IT Service Organizations: Implications for Service Design and Management beyond the IT Domain", Proceedings of the Nineteenth Americas Conference on Information Systems, 2013.

[5] J. F. Andry, "Performance Measurement of Information Technology Governance: A Case Study", Jurnal Sistem Informasi (Journal of Information Systems). Vol. 2, No. 12, hlm. 56-62, 2016.

[6] J. F. Andry, J. S. Suroso, D. Y. Bernanda, "Improving Quality of SMEs Information System Solution with ISO 9126", Journal of Theoretical and Applied Information Technology, Vol. 96, No. 14, hlm. 4610-4620, 2018.

[7] J. Loisa, Hosea, A. C. Claudio, Alvin, Anthonio, J. F. Andry, "Information Technology Security System Audit at PT. MNC Securities Using COBIT 4.1 DS5 Domain", Journal of Business and Audit Information Systems Vol. 1 No. 2, hlm. 12-20, 2018.

[8] The Art of Service, "ITIL V3 Foundation Complete Certification Kit: 2009”, Edition Study Guide Book and Online Course. The Art of Service, hlm 156, 2009.

[9] J. F. Andry dan B. Sanjaya, “Audit Tata Kelola TI Pada PT. Porto Indonesia Sejahtera Menggunakan Cobit Pada Domain PO”, Jurnal Ilmiah Teknologi Informasi Terapan, Volume III, No 3, 2017.

[10] T. Pradini, dan J. F. Andry, “Audit Sistem Informasi Front Office Pada World Hotel Menggunakan Kerangka Kerja COBIT 4.1", Ikraith-Informatika, Vol. 2, No. 1, hlm. 18-25, 2018.

[11] K. Christianto, dan J. F. Andry, "Evaluating Maturity Level Using Framework ITIL: A Case Study of Service Desk's" ,International Journal of Information Techonology and Business, Vol. 1, No.1, 2018.

[12] J. F. Andry, dan K. Christianto, "Audit Menggunakan Cobit 4.1 Dan Cobit 5 Dengan Case Study”, Teknosain, Yogyakarta, hlm. 75, 2018. 